\title{
NUBARIA CANAL DEVELOPMENT AND ITS IMPACTS ON NUBA THERMAL POWER PLANT COOLING SYSTEM
}

mohamed abdellatif

\begin{abstract}
The objective of this work is to investigate the impacts of the future widening of the Nubaria Canal on the cooling system (intakes/ \outfalls) behavior of the Nubaria Thermal Power Plant (NTPP) which consists of 3 modules, I, II, and III .

The experimental work shows that widening the canal system affects the heat dispersion in the low flow period as the flow velocity will be reduced. A proposed redesign of the outfall structure of module III was tested by the physical model. The new design includes a reduction in the width of the outfall structure, a change in its inclination to the flow direction and relocation of the outfall structure. The new configuration and arrangement of the outfall structure of module III helps in reducing the temperature rise at the far bank of the Nubaria Canal and to complies with the regulations stated by the environmental protection laws. Also, the cross flow velocity at the centerline of the new outfall structure of module III was recorded to be less than $0.3 \mathrm{~m} / \mathrm{s}$, thus meeting the navigation safety requirements.
\end{abstract}

